Mens

revue d'histoire intellectuelle de l'Amérique française

\title{
Les historiens révisionnistes et le rejet de la " canadianité " du Québec : réflexions en marge de la Genèse des nations et cultures du Nouveau Monde de Gérard Bouchard
}

\section{Damien-Claude Bélanger}

Volume 2, numéro 1, automne 2001

URI : https://id.erudit.org/iderudit/1024459ar

DOI : https://doi.org/10.7202/1024459ar

Aller au sommaire du numéro

Éditeur(s)

Centre de recherche en civilisation canadienne-française

ISSN

1492-8647 (imprimé)

1927-9299 (numérique)

Découvrir la revue

Citer ce compte rendu

Bélanger, D.-C. (2001). Compte rendu de [Les historiens révisionnistes et le rejet de la " canadianité » du Québec : réflexions en marge de la Genèse des nations et cultures du Nouveau Monde de Gérard Bouchard]. Mens, 2(1), 105-112. https://doi.org/10.7202/1024459ar 


\section{LES HISTORIENS RÉVISIONNISTES ET LE REJET DE LA «CANADIANITÉ» DU QUÉBEC : RÉFLEXIONS EN MARGE DE LA GENĖSE DES NATIONS ET CULTURES DU NOUVEAU MONDE DE GÉRARD BOUCHARD}

\section{DAMIEN-CLAUDE BÉLANGER Département d'histoire Université McGill}

«Genèse», voilà un mot fort ambitieux qui annonce d'emblée une réflexion profonde et qui rappelle au lecteur La genèse de la société québécoise (1993), l'important ouvrage du grand sociologue québécois Fernand Dumont (1927-1997). En effet, la Genèse des nations et cultures du Nouveau Monde $e^{i}$ du démographe, sociologue et historien Gérard Bouchard est un ouvrage remarquable. En 2000, il a remporté le Prix littéraire de la Gouverneure générale du Canada pour le meilleur essai ou étude de langue française.

L'ouvrage est imposant. D'ailleurs, nul ne saurait accuser Gérard Bouchard d'être un intellectuel qui manque d'envergure. À une époque marquée par les analyses prudentes et par l'atomisation de la discipline historique, il n'a pas peur des grandes synthèses et des réflexions pénétrantes. Chercheur doué et polyvalent, Bouchard sait passer de la microhistoire à la macrohistoire sans difficulté.

Dans sa Genèse des nations, qui nous servira ici de tremplin pour lancer une réflexion plus large sur l'une des lacunes fondamentales de l'historiographie québécoise contemporaine, Bouchard souligne, avec justesse, que la comparaison est un 
«procédé d'objectivation et d'enrichissement de la connaissance historique ${ }^{\prime} »$. Ainsi, il effectue une vaste étude comparative pour mieux situer l'évolution de l'identité et de la culture québécoises dans le cadre des «collectivités neuves». Celles-ci sont issues de la colonisation européenne en Amérique, en Afrique et en Océanie. À l'exception du Québec et de Porto Rico, ces «collectivités neuves» ont toutes accédé à l'indépendance.

D'ailleurs, le rêve d'un Québec indépendant se trouve en filigrane dans la Genèse des nations. Bouchard tente d'expliquer les facteurs, dont celui de l'emprise du traditionalisme défensif sur la vie culturelle et intellectuelle du Québec, qui ont entravé sa marche vers l'indépendance. Implicitement, il prétend qu'une nation ne peut s'épanouir que si elle acquiert l'indépendance politique. Au Québec, celle-ci serait à la fois la consécration et l'aboutissement logique d'une modernité d'abord embryonnaire, puis à partir de la Révolution tranquille, triomphante. Le progrès, incarné par la Révolution tranquille et l'indépendantisme, aurait finalement raison de la réaction, incarnée par le traditionalisme. L'évolution historique serait donc une lutte entre le progrès et la réaction où les forces progressistes finiront par triompher et engendrer la modernité. Fondamentalement, il s'agit là d'une vision téléologique de l'histoire du Québec qui s'apparente à la conception whig de l'histoire'2.

À l'instar d'un grand nombre de nos historiens contemporains, Gérard Bouchard est un partisan de l'indépendance du Québec. Sa conception de l'histoire et de la nation, qui jouit actuellement d'une grande influence dans les milieux intellectuels québécois, découle d'un néonationalisme purgé de toute référence canadienne-française. Une fois encore, un décalage entre la pensée et la réalité marque la vie intellectuelle du Québec. Enfermée dans le monde des idées, une bonne partie des intellectuels québécois puise son identité dans l'esprit du temps et dans les théories abstraites, plutôt que dans la réalité concrète ou historique.

Animée par Guy Frégault, Maurice Séguin et Michel Brunet, l'école historique dite «de Montréal» a longtemps été l'expression 
historiographique du néonationalisme québécois. Cependant, avec l'évolution de la pensée nationaliste québécoise, son volet historiographique a connu une mutation profonde. Avec le temps, l'école dite «révisionniste» a fini par dominer la profession historique au Québec. Née au début des années soixante-dix, cette nouvelle école s'intéresse peu aux thèmes privilégiés par l'école de Montréal, c'est-à-dire au «retard» du Québec et à l'infériorité économique des Canadiens français. Dorénavant, les révisionnistes veulent montrer que le Québec connaît un développement historique largement analogue à celui des autres sociétés nord-américaines. Au lieu de souffrir d'une multitude de retards, l'évolution de la société québécoise serait plus ou moins «normale». Cependant, la pensée révisionniste est loin d'être monolithique. Elle est traversée par plusieurs tendances. D'ailleurs, comme le souligne Ronald Rudin, Gérard Bouchard lui-même, comme plusieurs autres historiens, a déjà éprouvé un certain malaise à l'égard de la pensée révisionniste, notamment en ce qui concerne sa conception du religieux dans le développement historique du Québec. Pour mieux comprendre le processus de modernisation au Québec, «Bouchard [soutient] qu'il importait d'examiner le rôle néfaste de la religion dans l'histoire de la province ${ }^{3} »$. Toutefois, sa critique reste interne au révisionnisme. En effet, Bouchard fait partie de cette école qui domine l'historiographie québécoise depuis presque trente ans et sa Genèse des nations tente même d'en renouveler les pratiques. Pour l'historien Éric Bédard, il s'agirait même du magnum opus de cette école ${ }^{4}$.

D'ailleurs, la Genèse des nations de Bouchard illustre bien un des thèmes majeurs de l'historiographie révisionniste : le rejet de la «canadianité» du Québec. Ainsi, comme leurs ancêtres traditionalistes qui niaient l'américanité du Canada français, certains historiens révisionnistes perpétuent la longue tradition canadienne-française de négationnisme intellectuel en rejetant la «canadianité» du Québec. Même les critiques récents du révisionnisme passent sous silence ce rejet. Postmodernes, ils concentrent leurs attaques sur le modernisme historiographique des révisionnistes, leur quête excessive normalité et leur culte de la Révolution tranquilles. 
$\mathrm{La}$ «canadianité» est pourtant un élément incontournable du développement historique du Québec. Depuis la Confédération, elle est centrée sur deux éléments fondamentaux : la participation du Québec à une union fédérale et l'enracinement des Québécois francophones dans une nation culturelle (le Canada français) qui déborde largement le cadre territorial de la province de Québec. L'approche de Bouchard et d'un grand nombre d'historiens révisionnistes est d'ailleurs trop axée sur le territoire et l'État québécois. En effet, comme le souligne avec justesse un des premiers historiens révisionnistes, René Durocher, «nous savons qu'il y a de nombreux peuples ou nations sans État et que les deux réalités sont distinctes ${ }^{6} \gg$. Néonationalistes, certains historiens révisionnistes semblent refuser cette distinction essentielle à l'histoire du Québec. Sous prétexte d'ouverture, et en voulant fonder dans l'histoire la nation québécoise civique et territoriale, ils rejettent par la même occasion la «canadianité» québécoise, et finissent par négliger l'influence canadienne-anglaise ou fédérale sur le développement du Québec et l'apport québécois à la vie canadienne. De plus, ils passent sous silence le lien organique qui unissaient jadis le Québec français aux minorités françaises du continent américain. Sans tenir compte du volet canadien de l'histoire québécoise, nul historien ne peut prétendre faire de l'histoire nationale totale.

Dans La genèse des nations et cultures du Nouveau Monde, les conséquences néfastes du rejet de la «canadianité» du Québec apparaissent clairement lorsque, à titre d'exemple, l'auteur compare la marche du Canada vers l'autonomie à celle de la Nouvelle-Zélande. Sur cette question, ce rejet fausse l'analyse en créant une trop grande distinction entre l'identité canadienne et l'identité québécoise. Selon Bouchard, la Nouvelle-Zélande serait «la plus ancienne des collectivités neuves» parce que «de toutes les collectivités du Nouveau Monde, c'est celle qui a incarné le plus longtemps et le plus intégralement le modèle de la continuité avec la mère patrie ${ }^{7} »$. Toutefois, une bonne part de cette affirmation repose sur une analyse assez maladroite ${ }^{8}$. En effet, comme le concède néanmoins l'auteur, sans la pression du Canada français, la marche canadienne 
vers l'autonomie aurait probablement été moins rapide et, somme toute, comparable à celle de la Nouvelle-Zélande'. Ainsi, l'apport canadien-français au développement de l'identité canadienne est incontournable ${ }^{10}$. Il est donc difficile de justifier une comparaison entre le Canada et le Québec sur cette question. Ici, Bouchard compare deux histoires «nationales» évoluant en symbiose. En effet, l'histoire du Canada inclut celle du Québec. Évacuer la dimension canadienne de l'identité québécoise (ou vice-versa) est une erreur historiographique qui déforme notre passé. S'il est légitime et même souhaitable en histoire culturelle et intellectuelle de vouloir comparer le Canada anglais au Canada français, il est difficile, voire souvent impossible, de comparer le Québec au Canada. Nul ne peut nier que le Québec fait partie du Canada!

Le rejet de la «canadianité» se manifeste également chez Bouchard par son choix d'objets de comparaison. En effet, un certain goût pour «l'exotisme» se dégage de la Genèse des nations et cultures du Nouveau Monde. La part concédée au Canada (anglais), voire même aux États-Unis, dans cet ouvrage est, somme toute, assez restreinte. Inversement, beaucoup de place est accordée à l'Amérique latine, à l'Australie et sa sœur cadette, la Nouvelle-Zélande. Selon nous, l'analyse aurait pu être enrichie par une optique plus «canadienne». D'ailleurs, Bouchard affirme, à l'instar de Ramsay Cook "', que le Canada anglais, tout comme le Canada français, possède une «culture de la survivance ${ }^{12} \gg$. Toutefois, il ne pousse pas la réflexion jusqu'à sa conséquence logique, c'est-à-dire vers une comparaison plus approfondie de leur conception réciproque de la survivance. Celleci aurait probablement été plus féconde qu'une comparaison Québec-Argentine ou Québec-Australie. De plus, le développement de l'identité et de la culture acadiennes ou, mieux encore, de TerreNeuve auraient peut-être fourni à la démarche de Bouchard des outils de comparaison plus pertinents ${ }^{13}$.

Malheureusement, cette étude sur la genèse des nations et cultures du Canada devra attendre, car Bouchard, comme bien des historiens québécois, a tendance non seulement à marginaliser 
le Canada et à s'y désintéresser dans ses recherches, mais aussi à voir le Canada anglais de façon trop monolithique. Pourtant, le Canada anglais est une mosaïque complexe traversée par des tensions et des divisions. En fait, le Canada est une collectivité neuve formée à partir d'autres collectivités neuves (dont le Québec), et de certaines qui sont plus anciennes (les Premières Nations).

Dans l'ensemble, la réflexion de Bouchard, comme celle de bien des historiens québécois, serait plus féconde si elle était plus «canadienne». Dans un article récent, René Durocher soulignait avec raison que «le Québec est une nation, avec ou sans souveraineté étatique complète. Mais le Québec ne peut pas ne pas tenir compte de son intégration dans le Canada ${ }^{14}$.» En évacuant la dimension canadienne de leurs recherches, bien des historiens révisionnistes marginalisent une dimension fondamentale de l'histoire québécoise. Intégrer la trame historique canadienne à celle du Québec n'est pas forcément un acte politique, voire une profession de foi fédéraliste. D'ailleurs, la présente note de lecture n'est pas un appel au rejet d'une histoire axée sur le Québec. C'est plutôt une invitation à pratiquer une histoire plus intégrale ou totale, en l'occurrence, plus «canadienne». Il est tout à fait légitime que le Québec ou le Canada français soient au centre de l'analyse historique. Cependant, lorsque la «canadianité» du Québec est évacuée de l'analyse, une partie de sa richesse historique disparaît et sa compréhension en est réduite, sinon faussée.

\section{NOTES}

' Bouchard, Gérard. Genèse des nations et cultures du Nouveau Monde. Essai d'histoire comparée. Montréal, Boréal, 2000. 503 pages.

'Ibid., p. 38.

${ }^{2}$ Pour l'historien anglais Sir Herbert Butterfield, l'interprétation whig de l'histoire repose sur une «tendency in many historians [...] to emphasise certain principles of progress in the past and to produce a story which is the ratification if not the glorification of the present» (cité dans Peter Novick, That Noble Dream: The 
"Objectivity Question» and the American Historical Profession, Cambridge, Cambridge University Press, 1988, p. 13). Dans «the teleological "Whig interpretation of history," [...] historical actors [are] graded according to whether they [advance] or [retard] the growth of liberalism and democracy» (Novick, op. cit., p. 465). Pour mieux comprendre la conception whig de l'histoire, voir Herbert Butterfield, The Whig Interpretation of History, Londres, Bell, 1951 [1931], vi-132 p.

${ }^{3}$ Ronald Rudin, Faire de l'histoire au Québec, Sillery, Septentrion, 1998, p. 241.

${ }^{4}$ Éric Bédard, «Genèse des nations et cultures du Nouveau Monde: le magnum opus de l'historiographie moderniste», Bulletin d'histoire politique, vol. 9, n² (printemps 2001), pp. 160-173.

${ }^{5}$ Voir Bédard, loc. cit. et Jocelyn Létourneau, Passer à l'avenir. Histoire, mémoire, identité dans le Québec d'aujourd'hui, Montréal, Boréal, 2000, 194 p.

'René Durocher, «Une ou des histoires nationales», dans Robert Comeau et Bernard Dionne, dir. À propos de l'histoire nationale, Sillery, Septentrion, 1998, p. 85.

${ }^{7}$ Bouchard, op. cit., p. 330.

${ }^{8}$ Elle repose également sur quelques erreurs de faits. Par exemple, comme preuve de l'ultra-loyalisme néo-zélandais et de l'autonomisme canadien, Bouchard affirme que «lors de la Première Guerre mondiale, [la Nouvelle-Zélande] a pu décréter la conscription sans tenir de référendum, contrairement au Canada et à l'Australie» (page 332) et que «jusqu'en 1974, les nouveaux passeports [néo-zélandais] conservèrent la mention "British subject" sur la page couverture" (page 333). Or, le Canada n'a jamais tenu de référendum sur la conscription durant la Première Guerre mondiale. Même durant la Deuxième Guerre mondiale, nous n'avons tenu qu'un plébiscite sur une question nébuleuse qui soulève des difficultés d'interprétation. De plus, au début des années soixante-dix, le passeport canadien proclamait encore en première page que «les citoyens canadiens sont sujets britanniques».

'Sur cette question, l'historien canadien-anglais William Lewis Morton s'est montré particulièrement perceptif lorsqu'il écrivit en 1960 : «It is too little recognized that the French Canadian was the central figure in the evolution of self-government in Canada.» (W. L. Morton, The Canadian Identity, Madison et Toronto, University of Wisconsin Press et University of Toronto Press, 1961, p. 34). 
"Pour certains historiens nationalistes, dont Michel Brunet, il s'agit moins d'un apport que d'une appropriation par les Canadiens anglais d'une importante part de l'identité (jusqu'au nom «Canadien») et des symboles (castor et feuille d'érable) du Canada français. (Voir Michel Brunet, «Canadians et Canadiens» (1953), dans Canadians et Canadiens, Montréal, Fides, 1954, pp. 17-32).

"Voir Ramsay Cook, «La Survivance English-Canadian Style», dans The Maple Leaf Forever: Essays on Nationalism and Politics in Canada, Toronto, Macmillan, 1977 [1971], pp. 123-147.

${ }^{12}$ Bouchard, op. cit., p. 318.

${ }^{13}$ Une comparaison entre le Québec et Terre-Neuve pourrait s'avérer fascinante. Voilà une société neuve où l'identité nationale est très bien développée et qui possède ses propres mythes fondateurs et lieux de mémoire. L'Île de Terre-Neuve contient également une importante population catholique et sa marche vers l'autonomie a connu deux chocs insurmontables : la fin du gouvernement responsable et de l'indépendance terre-neuvienne en 1934 et son entrée dans la Confédération en 1949. En quelques années, Terre-Neuve est passée de l'indépendance à la dépendance la plus complète. Dans un certain sens, ces événements eurent le même effet sur le peuple terre-neuvien que la Conquête eut sur le Canada français. D'ailleurs, certains auteurs ont vu d'importantes similarités entre le discours traditionaliste du Canada français et celui de Terre-Neuve. (Voir S.J.R. Noel, Politics in Newfoundland, Toronto, University of Toronto Press, 1971, p. 257).

${ }^{14}$ Durocher, loc. cit., p. 89. 